\title{
Epidemiological, Clinical and Therapeutic Aspects of Arterial Hypertension at the General Medicine Department of Nzerekore Regional Hospital
}

\author{
Beavogui Mariama $^{*}$ (D), Balde Elhadj Yaya1, Doumbouya Idrissa ${ }^{2}$, Barry Ibrahima Sory ${ }^{1}$, \\ Samoura Aly1, Camara Abdoulaye1, Bah Mamadou Bassirou Mariama1, Sylla Ibrahima Sory1, \\ Balde Mamadou Dadhi', Bah Abdoul Mazid Mariama1, Kone Alpha3 ${ }^{3}$ Balde Mamadou Aliou1, \\ Conde Mamady 1
}

${ }^{1}$ Cardiology Department, Ignace Deen National Hospital, Conakry, Guinea

${ }^{2}$ Department of Neurology, Ignace Deen National Hospital, Conakry, Guinea

${ }^{3}$ Cardiology Department, Donka National Hospital, Conakry, Guinea

Email: ^beavoguimariama7@gmail.com

How to cite this paper: Mariama, B., Yaya, B.E., Idrissa, D., Sory, B.I., Aly, S., Abdoulaye, C., Mariama, B.M.B., Sory, S.I., Dadhi, B.M., Mariama, B.A.M., Alpha, K., Aliou, B.M. and Mamady, C. (2021) Epidemiological, Clinical and Therapeutic Aspects of Arterial Hypertension at the General Medicine Department of Nzerekore Regional Hospital. World Journal of Cardiovascular Diseases, 11, 533-538.

https://doi.org/10.4236/wjcd.2021.1111050

Received: September 26, 2021

Accepted: November 27, 2021

Published: November 30, 2021

Copyright () 2021 by author(s) and Scientific Research Publishing Inc. This work is licensed under the Creative Commons Attribution International License (CC BY 4.0).

http://creativecommons.org/licenses/by/4.0/

(c) (i) Open Access

\begin{abstract}
Introduction: High blood pressure is a public health problem in Guinea as well as everywhere in Africa. The objective of our study was to assess the epidemiological, clinical and therapeutic aspects of High blood pressure in the general medicine department of the Nzérékoré regional hospital. Methodology: This was a prospective study of a descriptive type, lasting 06 months, from July 1 to December 31, 2014. Results: We recorded 156 cases of High blood pressure among a total of 570 patients, for a hospital frequency of $27 \%$. The 56 - 65 age group was the most affected, at $29.4 \%$, with a predominance of men (sex ratio: 1.5). Alcoholism was the most common cardiovascular risk factor with a frequency of $51.2 \%$, smoking and physical inactivity were found in $35.8 \%$ and $30.7 \%$ respectively; psychosocial stress was found in $24.3 \%$ of patients. The clinic was dominated by headache (100\%) and dizziness (57.6\%). All our patients were subjected to a healthy diet. Fixed dual therapy was the most widely used treatment regimen, i.e. 91 patients (58.3\%) and included a diuretic in $37.1 \%$ of cases, a calcium channel blocker in $25 \%$ of cases and an ACE inhibitor in $24.3 \%$. Conclusion: This study revealed a high frequency of hypertension in the general medicine department of the regional hospital of N’zérékoré.
\end{abstract}

\section{Keywords}

Epidemiology, Clinical, Therapeutic, Hypertension 


\section{Introduction}

According to WHO, hypertension is an increase in blood pressure with systolic blood pressure greater than or equal to $140 \mathrm{mmHg}$ and/or diastolic blood pressure greater than or equal to $90 \mathrm{mmHg}$ [1].

Responsible for at least $45 \%$ of deaths from heart disease, $51 \%$ from stroke and $30 \%$ of deaths from kidney failure, it is currently a real public health problem around the world [2] [3] [4].

In the United States, between 1999 and 2000, the prevalence of hypertension was $33.5 \%$ in the black population aged 18 and over against $28.9 \%$ in the white population [5].

In France, the prevalence rate of hypertension was 31\% among adults aged 18 to 74 (34.1\% for men and $27.8 \%$ for women) [6].

In Africa, it represents nearly $44 \%$ of hospitalizations with hospital mortality estimated at 7\% [7]. Cohort studies in Nigeria and Zimbabwe show that 10 to 20 million people could be affected and that treatment could prevent around 250,000 deaths each year [8]. In Cameroon, the age-adjusted prevalence was $15.4 \%$ in rural areas and 19.1\% in urban areas [9]. A study carried out in Fouta Djalon in 2006 reported a frequency of $43.6 \%$ in urban areas and $14.9 \%$ in rural areas [4].

The objective of this study was to describe the epidemiological, clinical and therapeutic profile of patients in the general medicine department of the Nzérékoré regional hospital.

\section{Material and Methods}

The general medicine department of the Nzérékoré regional hospital served as the study framework for this study.

This was a prospective descriptive study, lasting 06 months, from July 1 to December 31, 2014 and involved all patients with blood pressure greater than or equal to $140 / 90 \mathrm{mmHg}$.

Were included, all patients hospitalized or seen on an outpatient basis with blood pressure greater than or equal to $140 / 90 \mathrm{mmHg}$, as well as patients already known to be hypertensive under treatment.

Our analysis focused on demographic data (age, sex), risk factors (alcoholism, smoking, diabetes, sedentary lifestyle, psychosocial stress, taking oral contraceptives), clinical signs on admission; the grade of hypertension, the treatment modalities.

We carried out a comprehensive recruitment in which data was collected using a pre-established survey sheet. These data were distributed as frequencies and were analyzed as percentages.

\section{Results}

During the study period, 570 patients were seen for consultation, of which 156 met our inclusion criteria, i.e. $27.3 \%$ of patients. The $56-65$ age group was the most affected, at $29.4 \%$, followed by the $46-55$ age group (23.7\%) (Table 1). 
There was a male predominance (60.9\%) with a sex ration of 1.5. More than half of the patients (51.2\%) were alcoholics, smoking and physical inactivity were found in $35.8 \%$ and $30.7 \%$ respectively; psychosocial stress was found in $24.3 \%$ of patients; diabetes in $17.3 \%$, oral contraceptives in $9.6 \%$ and obesity in $5.1 \%$ of patients (Table 2).

Clinical signs on admission were in Table 3 dominated by headache (100\%), dizziness (57.6\%), tinnitus (48.1\%), visual blurring (12.8\%), dyspnea (12,1\%) and palpitations (9.6\%).

Hypertension was grade I in $23.7 \%$, grade II in $59.7 \%$ and grade III in $16.6 \%$.

All our patients benefited from a healthy diet; dual antihypertensive therapy was used in 91 patients with a frequency of 58.3\%; 37 patients $(23.8 \%)$ received monotherapy and 28 patients $(17.9 \%)$ were on triple therapy. The most widely used classes of antihypertensive drugs were thiazide diuretics (37.1\%), followed by calcium channel blockers (25\%), ACE inhibitors (24.3), beta blockers (6.4\%).) and angiotensin receptor antagonists (3.2\%) (Table 4).

Table 1. Distribution of patients according to demographic data.

\begin{tabular}{ccc}
\hline Variables & Effective & Percentage (\%) \\
\hline Sex & 156 & 100 \\
Male & 95 & 60.9 \\
Female & 61 & 39.1 \\
\hline Age group (years) & 156 & 100 \\
\hline $16-25$ & 5 & 3.2 \\
$26-35$ & 14 & 8.9 \\
$36-45$ & 26 & 16.7 \\
$46-55$ & 37 & 23.7 \\
$56-65$ & 46 & 29.4 \\
$66-75$ & 20 & 12.9 \\
$76-85$ & 8 & 5.1 \\
Total & 156 & 100 \\
\hline
\end{tabular}

Table 2. Distribution of patients according to risk factors.

\begin{tabular}{ccc}
\hline Risk factors & Effective & Percentage (\%) \\
\hline Alcohol & 80 & 51.2 \\
Tobacco & 56 & 35.8 \\
Sedentary lifestyle & 48 & 30.7 \\
Psycho-social stress & 38 & 24.3 \\
Diabetes & 27 & 17.3 \\
Obesity & 8 & 5.1 \\
Oral contraceptives & 15 & 9.6 \\
\hline
\end{tabular}


Table 3. Distribution of patients according to clinical signs.

\begin{tabular}{ccc}
\hline Clinical signs & Effective & Percentage (\%) \\
\hline Headache & 156 & 100 \\
Dizziness & 90 & 57.6 \\
Ringing in the ears & 75 & 48.07 \\
Visual blur & 20 & 12.8 \\
Dyspnea & 19 & 12.1 \\
Palpitation & 15 & 9.6 \\
Vomiting & 9 & 5.7 \\
Edema of the lower limbs & 7 & 4.4 \\
Chest pain & 7 & 4.4 \\
Epigastric pain & 6 & 3.8 \\
Oliguria & 4 & 2.5
\end{tabular}

Table 4. Distribution of patients according to the classes of antihypertensive drugs used.

\begin{tabular}{ccc}
\hline Therapeutic classes & Effective & Percentage (\%) \\
\hline Diuretics & 58 & 37.1 \\
Calcium channel blockers & 40 & 25.6 \\
Converting enzyme inhibitors & 38 & 24.3 \\
Beta-blockers & 10 & 6.4 \\
ARA II & 5 & 3.2 \\
\hline
\end{tabular}

\section{Discussion}

During our study period, 570 patients were seen in consultation, 156 cases high blood pressure or a hospital frequency of 27\%. In the ESTEBAN study in 2015 in France, Perrine et al:; reported a frequency of hypertension of 32.3\% [10]. Our results are superior to those found by Damorou et al.; in Togo, which reported a hospital frequency of $22 \%$ [11]. Baldé et al:; during a survey carried out on a cohort of 669 subjects in the prefectures of Forécariah, Fria and Boké found 29\% of hypertensive patients [12].

The 56 - 65 age group was the most affected, at $29.4 \%$. This result shows the fact that hypertension increases with age as indicated by the data in the literature [13].

In our study there was a male predominance with a frequency of $60.89 \%$. Our results are different from those found by Twagirumukiza et al.; in Rwanda, which reported a female predominance of 59\% [14]. On the other hand, our results are comparable to those of Ikama et al.; in 2014 in Congo Brazzaville who found male predominance in $56.8 \%$. This male predominance is thought to be due to the fact that men are more exposed to cardiovascular risk factors [15]. 
Alcoholism was the main cardiovascular risk factor found (51.2\%). However Baldé et al:; reported 3\% alcoholism in a study involving 669 hypertensive patients [12]. This high proportion of alcoholism in our study is linked to the fact that the Nzérékoré region is a region where the consumption of alcoholic beverages is widespread. Sedentary lifestyle and smoking were found in $35.8 \%$, and $30.7 \%$ respectively. Ikama et al.; in 2014 found $44.4 \%$ sedentary and $4 \%$ smoking [15].

All our patients benefited from a healthy diet; dual antihypertensive therapy was used in 91 patients (58.3\%); 37 patients (23.8\%) received monotherapy and 28 patients (17.9\%) were on triple therapy. Based on ESC/ESH 2018 Guidelines for the management of high blood pressure fixed dual therapy (ACE inhibitor or ARB II combined in the same tablet with a calcium channel blocker or a thiazide or related diuretic) is the treatment of first choice. The only exceptions are frail elderly patients and the rare patients at high cardiovascular risk who would be prescribed treatment for normal-high blood pressure [16].

\section{Conclusion}

This study shows a high prevalence of hypertension in the general medicine department of the regional hospital of Nzérékoré. As it is a chronic pathology requiring continuous management and regular monitoring, it would be interesting to focus on primary prevention linked to risk factors within the population.

\section{Conflicts of Interest}

The authors declare no conflicts of interest regarding the publication of this paper.

\section{References}

[1] Houenassi, M., Azondekon, A., Gnangnon, A., Lawani, R., Sehonou, J., Atadokpede, F., et al. (2004) Direct Cost and Absenteeism Linked to Hypertension in Patients Receiving Care. Tropical Cardiology, 30, 19-23.

[2] Banach, M., Mikhailidis, D., Kjeldsen, S. and Rysz, J. (2009) Time for New Indications for Statins. Medical Science Monitor, 15, 1-5.

[3] World Health Organization (2008) Geneva: Causes of Death 2008.

[4] Balde, M.D., Balde, N.M., Kaba, M.L., Diallo, I., Diallo, M.M., Kake, A., et al. (2006) Arterial Hypertension: Epidemiology and Metabolic Abnormalities in Fouta Djalon in Guinea. Mali Médical, 21, 19-22.

[5] Hajjar, L. and et Kotchen, T.A. (2003) Trends in Prevalence, Awareness, Treatment, and Control of Hypertension in the United states, 1998-2000. JAMA, 290, 199-206. https://doi.org/10.1001/jama.290.2.199

[6] Godet, T.H., Vernay, M., Noukpoape, A., Salanave, B., Malon, A., Castetbon, K., et al. (2008) Blood Pressure Level: Average and Prevalence of Arterial Hypertension in Adults Aged 18 to 74, ENNS 2006-2007. BEH, 16, 478-483.

[7] Laurant, S., Giret, X. and et Thomas, D. (2003) Essential CME Day; DUO HTA Survey. Arch Evil Heart Will, 9, 823-831.

[8] Amah, G., Bernard, I. and et Levy, G. (2007) Particularity of Hypertension in Black 
African Subjects. Blood Thrombosis Vessels, 19, 10-16.

[9] Cooper, R., Rommi, C. and et Ataman, S. (1997) The Prevalence of Hypertension in Seven Populations of West African Orgin. American Journal of Public Health, 87, 160-168. https://doi.org/10.2105/AJPH.87.2.160

[10] Vallée, A., Gabet, A., Grave, C., Sorbets, E., Blacher, J. and Olié, V. (2020) Patterns of Hypertension Management in France in 2015: The ESTEBAN Survey. Journal of Clinical Hypertension, 22, 663-672. https://doi.org/10.1111/jch.13834

[11] Damorou, F., Pessinaba, S. and et Tcherou, T. (2001) Arterial Hypertension in Black Subjects Aged 50 and over in Lomé: Epidemiological Aspect and Cardiovascular Risk Assessment (Prospective and Longitudinal Study of 1485 Patients). Annales de Cardiologie et d' Angéiologie, 60, 61-66.

https://doi.org/10.1016/j.ancard.2010.07.002

[12] Baldé, A.M., Traoré, S. and et Touré, M. (2006) 1-Arterial Hypertension in Guinea: Epidemiology and Place of Phytotherapy in the Care in Urban and Rural Areas of Fria, Boke, Forecariah (Lower Guinea). Pharmacopé Médecine Traditionnelle Africaine, 12, 19-43.

[13] Broussol, C. and et Orgiazzi, J. (1990) Particularity of Arterial Hypertension in Diabetics. Médecine et Hygiène, 48, 681-685.

[14] Twagirumukiza, M. and et Gasakure, E. (2003) Aspects of Arterial Hypertension in the Internal Medicine Department at the Butaré University Hospital: Prospective Study, about 144 Cases in 2003. Medicine from Black Africa, 50, 169-175.

[15] Ikama, M.S., N'sitou, B., Makani, J., N'kala-Lambi, M. and et Passi-Louamba, C. (2014) 1-Arterial Hypertension and Level of Control in Brazzaville (Congo): Place of Blood Pressure Holter. Annales de Cardiologie et d’ Angéiologie, 64, 76-80. https://doi.org/10.1016/j.ancard.2015.01.007

[16] Williams, B., Mancia, G., Spiering, W., Rosei, E.A., Azizi, M., Burnier, M., et al. (2018) 2018 ESC/ESH Guidelines for the Management of Arterial Hypertension. Journal of Hypertension, 36, 1953-2041. https://doi.org/10.1097/HJH.0000000000001940 